University of Nebraska - Lincoln

DigitalCommons@University of Nebraska - Lincoln

\title{
Chemical Partitioning During Crystallization and its Effect on the Microstructure and Magnetic Behavior of Modified Nd-Fe-B Permanent Magnets
}

\author{
Jeffrey E. Shield \\ University of Nebraska-Lincoln, jshield@unl.edu \\ B. B. Kappes \\ University of Utah, Salt Lake City, UT \\ D. J. Branagan \\ Idaho National Engineering and Environmental Laboratory \\ J. Bentley \\ Metals and Ceramics Division, Oak Ridge National Laboratory, Oak Ridge, TN
}

Follow this and additional works at: https://digitalcommons.unl.edu/mechengfacpub

Part of the Mechanical Engineering Commons

Shield, Jeffrey E.; Kappes, B. B.; Branagan, D. J.; and Bentley, J., "Chemical Partitioning During Crystallization and its Effect on the Microstructure and Magnetic Behavior of Modified Nd-Fe-B Permanent Magnets" (2002). Mechanical \& Materials Engineering Faculty Publications. 15. https://digitalcommons.unl.edu/mechengfacpub/15

This Article is brought to you for free and open access by the Mechanical \& Materials Engineering, Department of at DigitalCommons@University of Nebraska - Lincoln. It has been accepted for inclusion in Mechanical \& Materials Engineering Faculty Publications by an authorized administrator of DigitalCommons@University of Nebraska Lincoln. 


\title{
Chemical partitioning during crystallization and its effect on the microstructure and magnetic behavior of modified $\mathrm{Nd}-\mathrm{Fe}-\mathrm{B}$ permanent magnets
}

\author{
J.E. Shield ${ }^{\mathrm{a}, *}$, B.B. Kappes ${ }^{\mathrm{b}}$, D.J. Branagan ${ }^{\mathrm{c}}$, J. Bentley ${ }^{\mathrm{d}}$ \\ ${ }^{a}$ Department of Mechanical Engineering, University of Nebraska, Lincoln, NE 68588 0656, USA \\ ${ }^{\mathrm{b}}$ Department of Materials Science and Engineering, University of Utah, Salt Lake City, UT 84112, USA \\ ${ }^{\mathrm{c}}$ Idaho National Engineering and Environmental Laboratory, Idaho Falls, ID 83415, USA \\ ${ }^{\mathrm{d}}$ Metals and Ceramics Division, Oak Ridge National Laboratory, Oak Ridge, TN 37831, USA
}

Received 2 October 2001; received in revised form 11 December 2001

\begin{abstract}
In this paper, the effect of alloy composition on the microstructural development of devitrified Nd-Fe-B-based alloys is investigated. While crystallization of simple ternary $\mathrm{Nd}_{2} \mathrm{Fe}_{14} \mathrm{~B}$ resulted in a highly variable microstructure and relatively poor demagnetization behavior, alloying additions, notably $\mathrm{Ti}$ and $\mathrm{C}$, were found to significantly refine and homogenize the crystallized microstructure. High spatial resolution energy dispersive X-ray spectroscopy revealed that partitioning to the grain boundaries led to the grain refinement by slowing interface kinetics. The more homogeneous grain structure resulted in improved demagnetization behavior, but segregating elements isolated grains and limited intergranular exchange coupling.
\end{abstract}

PACS: 75.50.Ww; 75.20.En; 75.30.Et

Keywords: Permanent magnets; Microstructural evolution; Alloying; Exchange interactions; Segregation

\section{Introduction}

In nanoscale bulk magnetic materials, intergranular exchange interactions can significantly affect the overall properties of the material. The dominance of intergranular exchange interactions leads to "exchange-spring" behavior and enhanced remanence and energy product as compared to non-interacting materials [1]. The requisites for

\footnotetext{
*Corresponding author.

E-mail address: jshield2@unl.edu (J.E. Shield).
}

effective intergranular exchange interactions include a nanoscale grain size $(<100 \mathrm{~nm})$ and grain boundaries free of second phases or impurity atoms that can lead to magnetic isolation of individual grains. Mechanical milling/alloying, rapid solidification, and devitrification of metallic glasses have all effectively generated appropriately fine nanostructures, resulting in exchange spring behavior. Further grain refinement and the production of more uniform nanostructures have been accomplished by the addition of alloying elements. For the $\mathrm{Nd}-\mathrm{Fe}-\mathrm{B}$ system, $\mathrm{Nb}, \mathrm{Ga}$ and $\mathrm{La}$ are a 
few examples of alloying additions that have effectively refined the grain size [2-7]. Additionally, combined metal carbide additions, notably $\mathrm{TiC}$, were found to significantly refine the grain structure in as-solidified $\mathrm{Nd}-\mathrm{Fe}-\mathrm{B}$ [8], $\mathrm{Sm}-\mathrm{Fe}$ [9], and $\mathrm{Pr}-\mathrm{Co}[10]$ alloys. A significant increase in glass forming ability was also observed in both $\mathrm{Nd}-\mathrm{Fe}-\mathrm{B}$ [11] and $\mathrm{Sm}-\mathrm{Fe}$ [12] alloys with the addition of $\mathrm{TiC}$. The degree of refinement was found to depend on the specific metallic addition in melt spun $\mathrm{Sm}-\mathrm{Fe}$ alloys with metal carbide additions, suggesting that metal carbide additions inhibit grain growth [13]. Measurement of solidliquid interface velocities in $\mathrm{Nd}-\mathrm{Fe}-\mathrm{B}$ indicated that the metal carbide slows the growth rate of crystallites in $\mathrm{Nd}-\mathrm{Fe}-\mathrm{B}$ [14], presumably due to segregation of the metal and/or carbide to the interface.

Segregation of alloying elements would have profound affects on the magnetic properties. Grain boundary segregation of $\mathrm{Cr}$ in, for example, $\mathrm{CoCrPt}$ magnetic recording media limits intergranular exchange interactions, magnetically isolating individual grains $[15,16]$. While this advantageously maintains sufficient coercivity in magnetic media, inhibiting intergranular exchange interactions negates the advantage of exchange spring permanent magnets, namely a higher remanence. In this paper, we examine the impact of alloying elements in the microstructural evolution and intergranular exchange behavior in $\mathrm{Nd}-\mathrm{Fe}-\mathrm{B}$ permanent magnets.

\section{Experimental procedures}

Three alloy compositions were investigated. The first, a ternary Nd-Fe-B alloy, had a nominal composition, in weight percent (wt $\%$ ), of $72.3 \mathrm{Fe}$, 26.7 Nd and $1 \mathrm{~B}$, which corresponds to the $2: 14: 1$ stoichiometry. The second composition added $2.5 \mathrm{wt} \% \mathrm{Ti}$ and $0.6 \mathrm{wt} \% \mathrm{C}$ to the stoichiometric composition (this corresponds to a 1:1 atomic ratio of $\mathrm{Ti}$ to $\mathrm{C}$ ). The final alloy was a nine component alloy with a composition (in wt $\%$ ) of 60.2 Fe, 6.9 Co, 14.8 Nd, 9.9 Pr, 3.0 Dy, 1.2 B, 2.4 $\mathrm{Ti}, 0.8 \mathrm{Zr}$ and $0.8 \mathrm{C}$. This composition is slightly transition metal-poor $(\mathrm{Fe}$ and $\mathrm{Co})$ relative to the
2:14:1 stoichiometry. The alloys were pre-alloyed by arc-melting high purity elemental constituents under a high purity Ar atmosphere. Arc melted buttons were subsequently melt spun at $30 \mathrm{~m} / \mathrm{s}$ in $1 \mathrm{~atm}$ ultra-high purity Ar. The as-solidified samples were examined by X-ray diffraction in a Philips X'Pert MPD utilizing $\mathrm{Cu} \mathrm{K}_{\alpha}$ radiation. A Perkin-Elmer System 7 differential thermal analyzer was utilized to characterize the thermal behavior. The heating rate was $10^{\circ} \mathrm{C} / \mathrm{min}$. Crystallization was achieved by heat-treating the alloys $5^{\circ} \mathrm{C}$ above their respective onset temperatures determined by DTA for appropriate lengths of time. Complete crystallization was determined by DTA; when no exothermic peak was observed, the sample was deemed crystallized. The detection limit for any amorphous fraction was estimated to be on the order of $1 \%$ or $2 \%$. The heat treatments were accomplished by wrapping the samples in $\mathrm{Ta}$ foil then sealing the wrapped samples in quartz ampoules under UHP Ar. The ampoules were then inserted into a pre-heated horizontal tube furnace. Samples were quenched in water at the conclusion of the heat treatment. X-ray diffraction was utilized to determine phase evolution upon crystallization.

Transmission electron microscopy specimens were prepared by ion milling individual ribbon pieces mounted on $\mathrm{Cu}$ ovals. Typical milling times were $7-8 \mathrm{~h}$ at $4.5 \mathrm{kV}$ on a liquid nitrogen-cooled stage. General microstructures were evaluated using a JEOL 2000FXII operating at $200 \mathrm{kV}$. The chemical profiles were obtained utilizing a Philips CM200 FEG STEM operating at $200 \mathrm{kV}$. The nominal probe size in STEM mode was $1.5 \mathrm{~nm}$ with a beam current of $1.2 \mathrm{nA}$. Data were taken at a step size of $2 \mathrm{~nm}$.

Magnetic measurements were taken on samples initially magnetized in a $35 \mathrm{kOe}$ pulsed field. Recoil measurements were performed using the DC demagnetization technique [17] with incremental fields of $400 \mathrm{Oe}$ up to $20 \mathrm{kOe}$ in a Lakeshore vibrating sample magnetometer. For the magnetic measurements, 15-20 ribbon pieces were mounted on the sample rod with adhesive tape so that the magnetic field was applied along the long axis of the ribbon. With this configuration, demagnetization factors were assumed to be negligible. 


\section{Results and discussion}

The as-solidified samples were nominally amorphous, as determined by X-ray diffraction, although the simple ternary alloy displayed some crystallinity. The heat of formation of the ternary alloy, however, was approximately $95 \%$ of the heats of formation of the other two alloys, suggesting that the crystalline fraction was on the order of $5 \%$ for the ternary alloy. The addition of $\mathrm{Ti}$ and $\mathrm{C}$ has been shown to improve the glass formability and stability, and that is what was observed here as well. The crystallization onset temperature was significantly higher for the TiCbearing samples $\left(621^{\circ} \mathrm{C}\right.$ and $\left.625^{\circ} \mathrm{C}\right)$ as compared to the ternary alloy $\left(560^{\circ} \mathrm{C}\right)$. Only a single crystallization event was observed in all cases. The kinetics, however, were significantly different, as $\mathrm{t}_{100}$ (the time to $100 \%$ crystallinity) was 16,26 and $6 \mathrm{~min}$ for the ternary, quinternary and nine component alloys, respectively. X-ray diffraction of the crystallized samples revealed only the presence of the tetragonal $\mathrm{Nd}_{2} \mathrm{Fe}_{14} \mathrm{~B}$-type compound (Fig. 1).

The microstructures that resulted from the specific crystallization processes are shown in Fig. 2, and the average grain sizes are shown in Table 1 . The ternary alloy showed a larger average grain size, and a greater variability in grain size, as

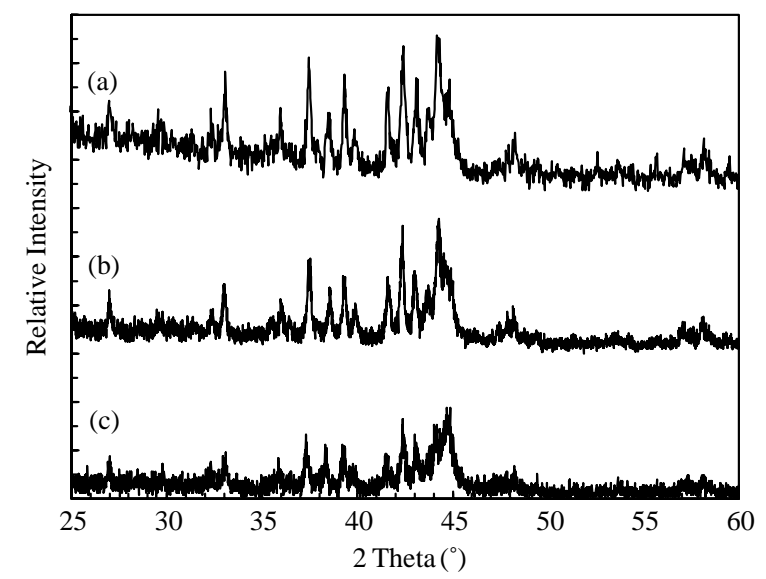

Fig. 1. X-ray diffraction patterns of crystallized (a) $\mathrm{Nd}-\mathrm{Fe}-\mathrm{B}$, (b) $\mathrm{Nd}-\mathrm{Fe}-\mathrm{B}-\mathrm{Ti}-\mathrm{C}$, and (c) $\mathrm{Nd}-\mathrm{Pr}-\mathrm{Dy}-\mathrm{Fe}-\mathrm{Co}-\mathrm{B}-\mathrm{Ti}-\mathrm{Zr}-\mathrm{C}$ alloys. compared to the other two alloys. Several extremely large grains are evident in Fig. 2(a). The quinternary and nine-component alloys displayed a refined grain size, and a relatively small size distribution. Clearly, the addition of the alloying elements resulted in a more refined and uniform microstructure.

The role of the alloying additions in refining the crystallized microstructure was investigated by EDS line profiles across the grain boundaries. The ternary alloy displayed uniform $\mathrm{Nd}$ and $\mathrm{Fe}$ concentrations across the grain boundaries (Fig. 3). However, alloying additions profoundly influence the grain boundary chemistry. Alloying additions to form the quinternary and ninecomponent alloys resulted in elemental partitioning at the grain boundaries. Especially noteworthy is the segregation of $\mathrm{Ti}$ and $\mathrm{C}$ to the grain boundaries (Fig. 4). Slight enrichment in the rare earth element was also observed at the grain boundary at approximately $20 \mathrm{~nm}$ (note that possibly another grain boundary was crossed at approximately $30 \mathrm{~nm}$, as indicated by a slight enrichment of rare earth) (Fig. 5). The concentration profile of $\mathrm{Fe}$ had significant variations, making its behavior difficult to ascertain. However, some depletion might be interpreted from Fig. 5, especially since the depletion appears to mirror changes in the rare earth. Also in the ninecomponent alloy, the grain boundary showed a slight depletion in Co (Fig. 4).

A material's microstructure largely influences the magnetic properties, especially with respect to the reversal process. The microstructural effects on the demagnetization behavior are evident in these alloys, as shown by the demagnetization curves of Fig. 6. The more uniform microstructures of the quinternary and nine-component alloys resulted in more square demagnetization behavior, and subsequently a smaller distribution of switching fields (Fig. 7). Additionally, the abnormally large grains in the ternary alloy (Fig. 2(a)) are above the single domain limit and thus are likely multidomain, which eases the demagnetization process in this alloy and leads to its poor demagnetization behavior shown in Fig. 6. The full loop for this alloy consisted of wasp-waist behavior. The presence of large, multidomain grains also leads 

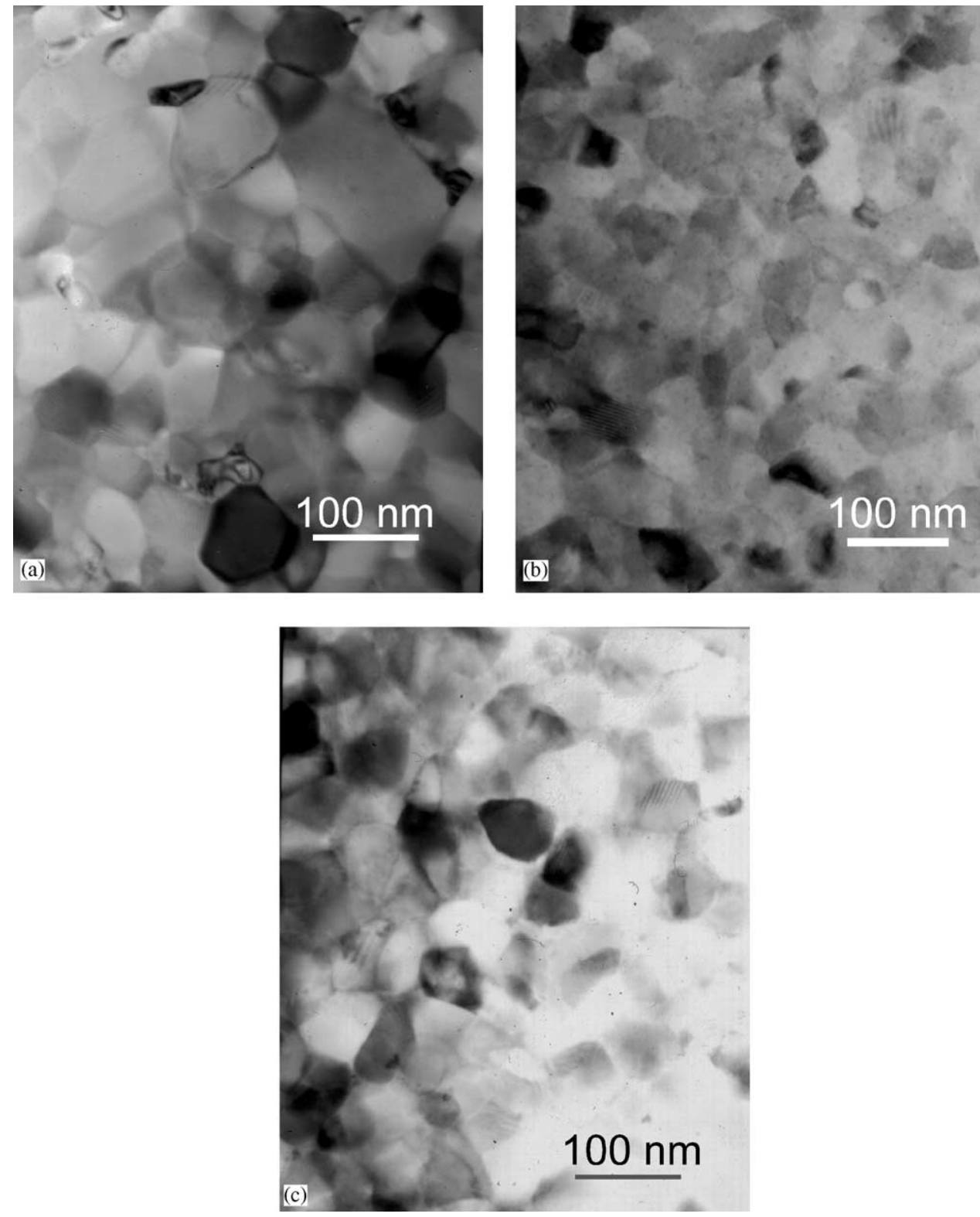

Fig. 2. TEM bright field micrographs of crystallized (a) Nd-Fe-B, (b) Nd-Fe-B-Ti-C, and (c) Nd-Pr-Dy-Fe-Co-B-Ti-Zr-C alloys.

to the low-field peak in the irreversible susceptibility of the ternary alloy evident in Fig. 7, while the higher field peak is due to reversal of singledomain grains. The single-peak behavior for the quinternary and nine-component alloys reflects the more homogeneous microstructures in these alloys. The higher coercivity and lower remanence
Table 1

Average grain sizes for the samples studied, as determined by transmission electron microscopy

\begin{tabular}{ll}
\hline Sample & Grain size $(\mathrm{nm})$ \\
\hline Nd-Fe-B & $77 \pm 30$ \\
Nd-Fe-B-Ti-C & $45 \pm 12$ \\
Nd-Pr-Dy-Fe-Co-B-Ti-Zr-C & $60 \pm 13$ \\
\hline
\end{tabular}




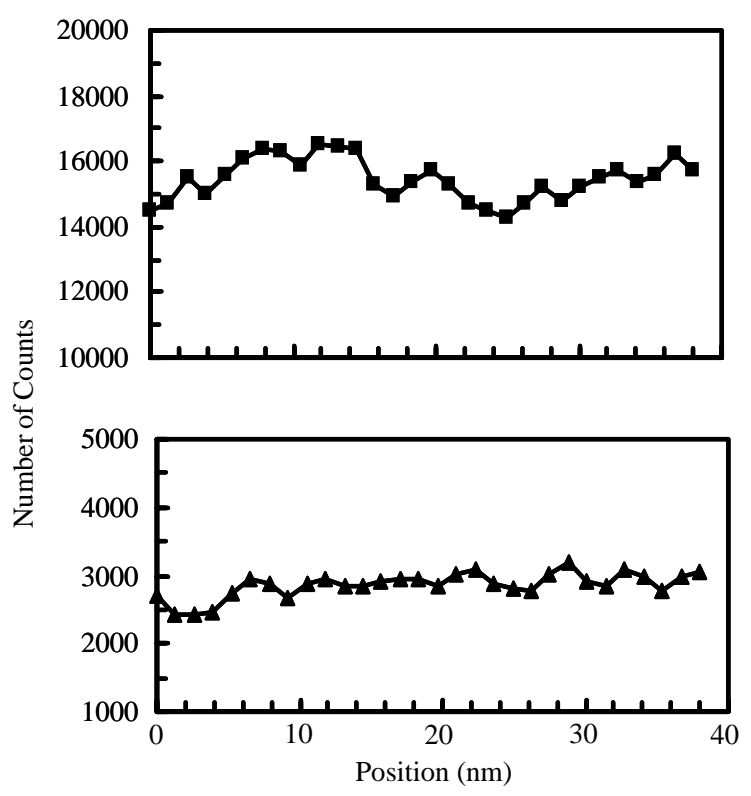

Fig. 3. Chemical profiles for $\mathrm{Fe}(\boldsymbol{\square})$ and $\mathrm{Nd}(\boldsymbol{\Delta})$ across a grain boundary in the ternary $\mathrm{Nd}-\mathrm{Fe}-\mathrm{B}$ sample. The grain boundary was at approximately $20 \mathrm{~nm}$.

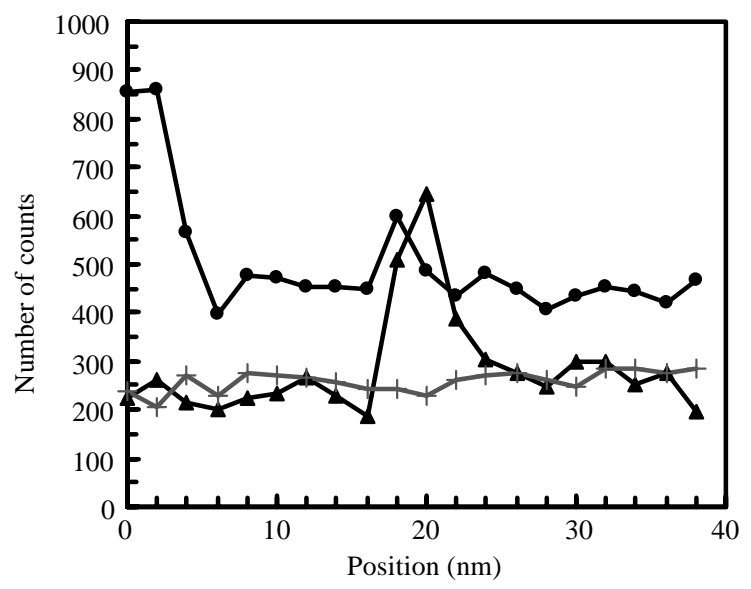

Fig. 4. Chemical profiles for Ti $(\mathbf{\Delta}), \mathrm{C}(\bullet)$ and $\mathrm{Co}(+)$ across a grain boundary in the nine component alloy. The grain boundary was at approximately $20 \mathrm{~nm}$.

of the nine-component alloy is largely due to Dy [18].

Intergranular exchange coupling can also explain the reduced coercivity of the ternary alloy when compared to the alloyed samples. Lower coercivity is generally associated with intergranu-

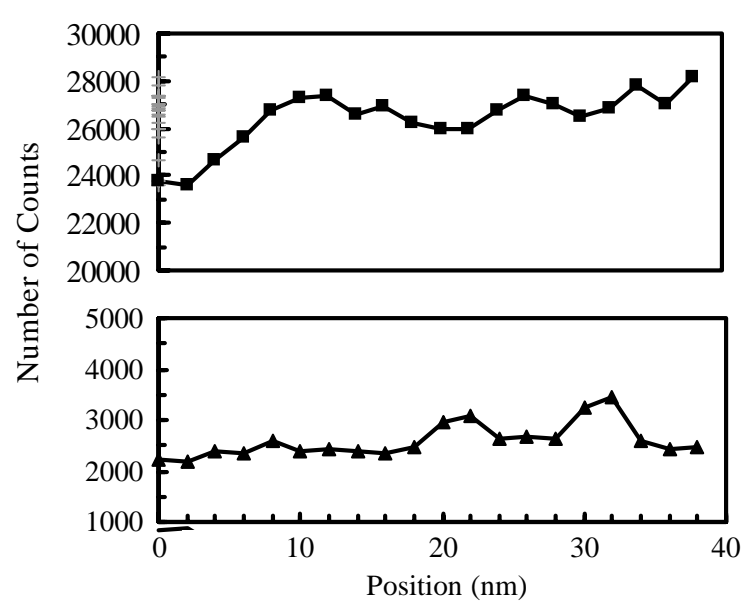

Fig. 5. Chemical profiles for $\mathrm{Fe}(\boldsymbol{\square})$ and total rare earth $(\boldsymbol{\Delta})$ across a grain boundary in the nine component alloy. The grain boundary was at approximately $20 \mathrm{~nm}$.

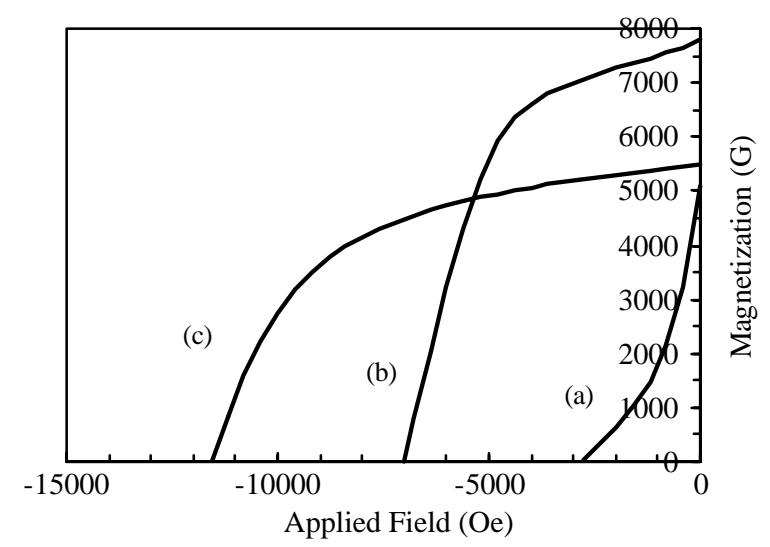

Fig. 6. Demagnetization curves for (a) $\mathrm{Nd}-\mathrm{Fe}-\mathrm{B}$, (b) $\mathrm{Nd}-\mathrm{Fe}-$ B-Ti-C, and (c) Nd-Pr-Dy-Fe-Co-B-Ti-Zr-C alloys.

lar exchange coupling, as reversal in one grain can lead to reversal in adjoining grains. DC demagnetization measurements effectively reveal intergranular exchange by monitoring domain wall processes during reversal [17]. Domain wall processes are possible in nanoscale grain structures due to the development of interaction domains in which several grains, through intergranular exchange interactions, establish a common "average" magnetization direction. Domain walls in turn sweep through these interaction domains so 


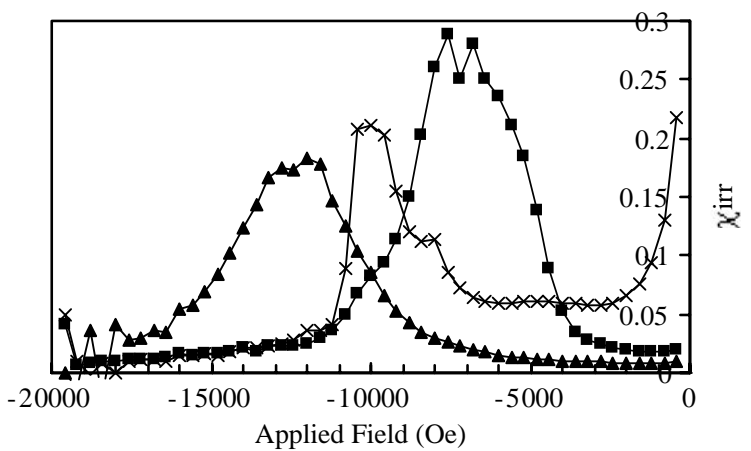

Fig. 7. Irreversible susceptibility as a function of magnetic field for $\mathrm{Nd}-\mathrm{Fe}-\mathrm{B}(\boldsymbol{\square}), \mathrm{Nd}-\mathrm{Fe}-\mathrm{B}-\mathrm{Ti}-\mathrm{C}(\boldsymbol{\square})$, and $\mathrm{Nd}-\mathrm{Pr}-\mathrm{Dy}-\mathrm{Fe}-$ $\mathrm{Co}-\mathrm{B}-\mathrm{Ti}-\mathrm{Zr}-\mathrm{C}(\mathbf{\Delta})$ alloys.

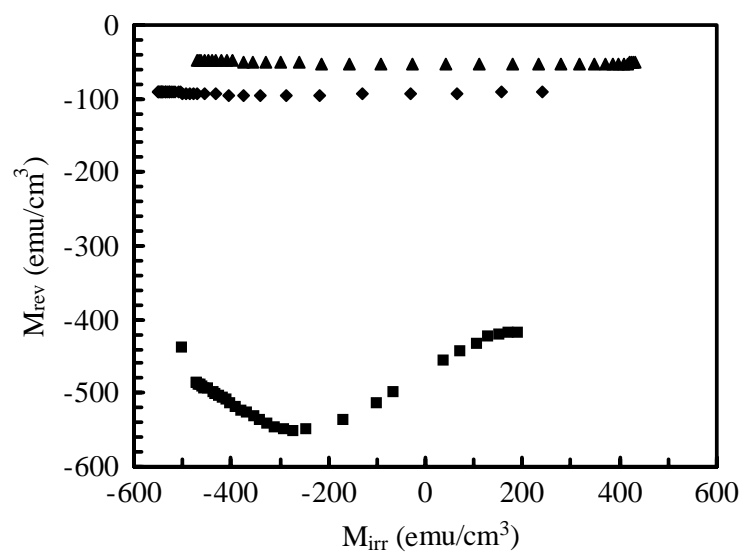

Fig. 8. Reversible magnetization $\left(M_{\text {rev }}\right)$ as a function of irreversible magnetization $\left(M_{\text {irr }}\right)$ for $\mathrm{Nd}-\mathrm{Fe}-\mathrm{B}(\boldsymbol{\square}), \mathrm{Nd}-\mathrm{Fe}-$ $\mathrm{B}-\mathrm{Ti}-\mathrm{C}(\bullet)$, and $\mathrm{Nd}-\mathrm{Pr}-\mathrm{Dy}-\mathrm{Fe}-\mathrm{Co}-\mathrm{B}-\mathrm{Ti}-\mathrm{Zr}-\mathrm{C}(\boldsymbol{\Delta})$ alloys.

that domain wall processes contribute to the magnetic reversal.

The magnetic reversal dynamics can be elucidated from $M_{\text {rev }}$ vs. $M_{\text {irr }}$ curves [19]. Non-linear behavior has been interpreted as the presence of domain wall processes, while linear behavior indicates reversal by rotation [19]. The nonlinearity develops as domain walls are impeded by crystal defects or grain boundaries that can act as pinning sites. Fig. 8 shows the $M_{\text {rev }}$ vs. $M_{\text {irr }}$ curves for the three alloys at a reverse field of 6000 Oe. The ternary alloy displays significant non-linearity, indicating that domain wall processes are active in the reversal process. In this case the observed non-linearity is due to the development of interaction domains, with the crystallographic misorientation between grains acting as pinning sites. While this ternary material contains some fraction of grains with sizes above the single domain limit, the absence of crystal defects within grains would result in free movement of domain walls. Hence, the non-linearity for the ternary alloy in Fig. 8 is not due to the domain wall motion in a few large grains, but rather from grain boundary pinning of interaction domain walls. The ternary alloy shows a much higher range in $M_{\text {rev }}$ over the extent of $M_{\text {irr }}$, indicating much more intergranular interaction, or "springiness". The curves for the quinternary and nine-component alloys display very little curvature and range in $M_{\text {rev }}$ (Fig. 8). This indicates very weak intergranular exchange and mostly single-domain behavior. The isolated grains result from the chemical partitioning (Fig. 4), as impurity atoms at the interface impede the intergranular exchange. The isolated grains thus lead to the higher coercivity observed in the alloyed samples. Additionally, a variation in stoichiometry of the 2:14:1 phase near the grain boundary may alter the intrinsic anisotropy constant $\left(K_{1}\right)$. This region of reduced (enhanced) anisotropy may pin (repel) domain walls, which can enhance coercivity and may in part explain the slight curvature (indicating domain wall processes) in the alloyed samples. Further work to clarify this latter point is necessary.

\section{Conclusions}

The glass-forming ability was improved for $\mathrm{Nd}-$ $\mathrm{Fe}-\mathrm{B}$ alloys by the addition of alloying elements. In addition, the alloying additions were found to significantly improve the microstructural development during devitrification, with finer and more uniform grains the result. The grain refinement was the result of segregation during crystallization, notably of $\mathrm{Ti}$ and $\mathrm{C}$, providing a grain boundary drag effect on the growing crystal interface. The more uniform microstructures resulted in a more square demagnetization behavior and a smaller distribution of switching fields for the modified 
alloys. However, the segregation in the modified alloys partly isolated the grains, inhibiting intergranular exchange coupling. Thus, alloying elements can effectively induce more uniform and refined nanostructures critical to exchange-spring permanent magnets, but can in turn inhibit intergranular exchange interactions, thereby negating the effects of a finer grain structure. Optimal heat treatments may reduce the segregation or cause precipitation of, for example, TiC, resulting in "cleaner" grain boundaries and enhanced intergranular exchange interactions.

\section{Acknowledgements}

This work was supported in part by the National Science Foundation through grant no. DMR9714946. This work was also supported in part by the Office of Basic Energy Sciences, US Department of Energy, under contract no. DEAC07-99ID13727 with INEEL managed by Bechtel BWXT Idaho, LLC, and at the ORNL SHaRE Collaborative Research Center sponsored by the Division of Materials Sciences and Engineering, US Department of Energy, under contract DEAC05-00OR22725 with UT-Battelle, LLC and through the SHaRE Program under contract DE-AC05-00OR00033 with Oak Ridge Associated Universities.

\section{References}

[1] E.F. Kneller, R. Hawig, IEEE Trans. Magn. 27 (1991) 3588 .
[2] Z.M. Chen, Y. Zhang, Y.Q. Ding, G.C. Hadjipanayis, Q. Chen, B.M. Ma, J. Magn. Magn. Mater. 195 (1999) 420.

[3] J.F. Liu, H.A. Davies, Proceedings of the 13th International. Workshop on Rare Earth Magnets and Their Applications, University of Birmingham, 1994, p. 79.

[4] J. Bernardi, T. Schrefl, J. Fidler, Th. Rijks, K. deDort, V. Archambault, D. Pere, S. David, D. Givord, J.F. O'Sullivan, P.A.I. Smith, J.M.D. Coey, U. Czernik, M. Gronefeld, J. Magn. Magn. Mater. 219 (2000) 186.

[5] W.L. Liu, Y.L. Liang, B.M. Ma, C.O. Bounds, IEEE Trans. Magn. 28 (1992) 2154.

[6] W.C. Chang, S.H. Wu, B.M. Ma, C.O. Bounds, J. Magn. Magn. Mater. 167 (1997) 65.

[7] K.H.J. Buschow, in: K.H.J. Buschow (Ed.), Handbook of Magnetic Materials, Vol. 10, Elsevier, Amsterdam, 1997, p. 463.

[8] D.J. Branagan, R.W. McCallum, J. Magn. Magn. Mater. 146 (1995) 89.

[9] J.E. Shield, C.P. Li, D.J. Branagan, J. Magn. Magn. Mater. 188 (1998) 353.

[10] B.E. Meacham, J.E. Shield, D.J. Branagan, IEEE Trans. Magn. 37 (2001) 2503.

[11] D.J. Branagan, R.W. McCallum, J. Alloys Compounds 244 (1996) 40.

[12] J.E. Shield, J. Alloys Compounds 291 (1999) 222.

[13] B.E. Meacham, Ph.D. Dissertation, University of Utah, 2001.

[14] O. Filip, R. Hermann, L. Schultz, J. Magn. Magn. Mater. 234 (2001) 247.

[15] M.R. Kim, S. Guruswamy, K.E. Johnson, IEEE Trans. Magn. 29 (1993) 3673.

[16] J.E. Wittig, T.P. Nolan, C.A. Ross, M.E. Schabes, K. Tang, R. Sinclair, J. Bentley, IEEE Trans. Magn. 34 (1998) 1564.

[17] D.C. Crew, P.G. McCormick, R. Street, J. Appl. Phys. 86 (1999) 3278.

[18] R. Coehoorn, D. de Waard, J. Magn. Magn. Mater. 83 (1998) 228.

[19] D.C. Crew, L.H. Lewis, J. Appl. Phys. 87 (2000) 4783. 